METALLURGY AND FOUNDRY ENGINEERING - Vol. 36, 2010, No. 1

Krzysztof Stefański*, Wiktor Kubiński**

\title{
DIMINISHMENT OF INTERNAL POLYGONIZATION OF TUBES IN HOT STRETCH-REDUCING MILL
}

\section{INTRODUCTION}

The hot stretch-reducing of steel tubes is performed usually in temperature of 900 to $1000{ }^{\circ} \mathrm{C}$ according to flow chart as shown on Figure 1. Material is rolled at the same time in at least two stands or in bigger number of stands. Quantity of stands depends on the requirements of the process and can vary from two stands to thirty-two in case of some complex drives of stretch reducing mill systems with the widest diameter range of rolled tubes.
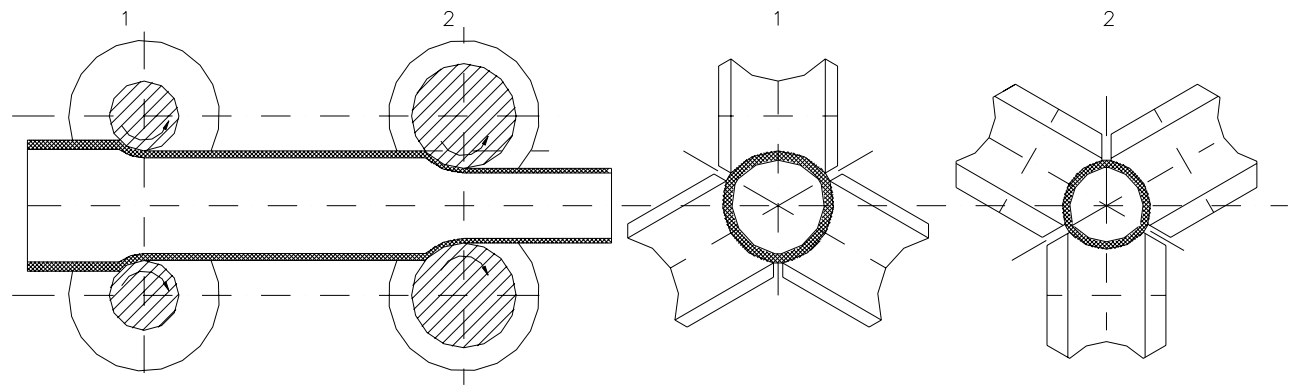

Fig. 1. The scheme of stretch reduction rolling

In each stand as a result of rolls pressure on rolled material, plastic deformation of material occurs reflecting shape of roll groove in a stand. Adequately increased rolls rotation speed resulting from the reduction of rolled tube diameter causes formation of tensile stress in axial direction in the wall of tube and wall thickness reduction. The tube which is

* M.Sc.: ArcelorMittal Tubular Products, Krakow, Poland; e-mail: kstefanski@poczta.onet.pl

** Ph.D., D.Sc.: Faculty of Management, AGH - University of Science and Technology, Krakow, Poland; e-mail: Wkubinsk@zarz.agh.edu.pl 


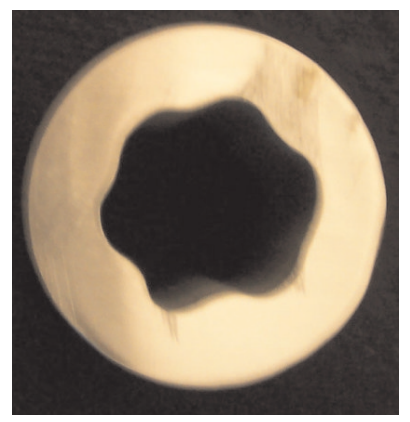

Fig. 2. Cross-section of thickened end with internal polygonization being rolled is empty inside. Natural effect which accompanies passing of the tube through the rolling stand is the increase of wall thickness. This increase of wall thickness will not be equal at all cross-sections and differences between separated zones on the perimeter of the tube for each of the three rolls will be the similar dependent on which zone is at the bottom or at the edge of roll grove. Differences between those two places will be the greatest and will create internal polygon in the tube (Fig. 2).

For individual case of calibrating/sizing the rolls grove, which indeed influences the course of forming of tube wall, the essential parameter which decides about final wall thickness of rolled tube is inter-stand tension. Increase of

inter-stand tension will diminish the effect of wall thickness increase or even reduce wall thickness with appropriate value of this inter-stand tension in case of adequately great reduction of diameter which by summing up the values of friction forces gives the possibility to transmit much more forces of tension between stands. The subject of this study are the results of several experiments which aim was to demonstrate that reduction rolling of tubes in the same conditions, using the same material but different values of inter-stand tension together with decrease of inter stand tension will increase the internal polygonization. Application of maximal inter-stand tension as a result of equilibrium of axial forces leads to minimizing the value of polygonization.

\section{INTERNAL POLYGONIZATION OF TUBES DURING HOT STRETCH REDUCING ROLLING}

Figure 2 presents a special case of internal polygonization of tubes which takes place during rolling of the thickened end. In this case head of rolled tube passed through 15 stands without inter-stand tension with rolling reduction of mostly $9.5 \%$. The cross section of thickened end which is shown on Figure 2 was made at the distance of $200 \mathrm{~mm}$ from the beginning of the tube while the distance between planes of axis of rolling mill stands amounted to $360 \mathrm{~mm}$. Average wall thickness in this place is about twice bigger than the wall thickness of mother tube. The case of rolling the thickened end according to Figure 2 shows the importance of inter-stand tension in stretch reduction of tubes. Thickened ends, which minimal length is equal to the distance between stands in case of two stands and depends on total reduction of tube rolled by a large number of stands, constitute scrap material increasing the cost of tube rolling. This is particularly painful in case of small lengths of mother tubes.

As demonstrated in the study [1], during the tube passing through one stand without inter-stand tension, the wall thickness is being diversified on the width of roll grove as a result of heterogeneous deformation of tube wall. In the middle of the roll grove the thickening of rolled tube wall is considerably smaller than at the edge of roll grove. Because 
the following stands of rolling mill are positioned by the angle of $\pi / 3$ (see Fig. 1) in relation to each other, thus zones with smaller and bigger thickened wall overlay each other finally creating the tube internal polygon. The reason of formation of internal hexagon so called polygon (Fig. 2) is differential in linear velocity between roll and tube at each point of roll surface on the width of roll grove and on the length of contact arc of metal and roll, except for neutral line, which separate contact areas of metal and roll into one where the line velocity of roll is smaller than the metal velocity and one where the line velocity of roll is bigger than the metal velocity. This fact especially intensely influences the wall thickening during passing of tube through roll grove with no inter-stand tension. In this case the location of neutral line on which lines velocities of roll and material are the same is at internal plane of the stand in the half of the angle of encircling the half of roll grove i.e. at the distance of $\pi / 6$ from the axis of roll grove of each of rolls in the stand. With the application of inter-stand tension the location of neutral line changes till its complete removal, which takes place when line velocities of roll and tube are the same in the place of input and output from roll gap. It occurs when the tube is subject to maximum braking at initial stands or maximum of drawing by further stands. Exceeding the optimal range of inter stand tension can cause sliding of roll or tube discontinuity in case of too much reduction i.e. when rolling reduction is big and cross section of rolling of tube is small or plasticity of rolling of material is not sufficient. The internal polygonization is determined by value $\mathrm{P}$ which is measured and calculated using method published in the study [2] according to the following formula (1):

$$
\mathrm{P}=\mathrm{S}_{\mathrm{bm}}-\mathrm{S}_{\mathrm{am}} / \mathrm{S}_{\mathrm{bm}}+\mathrm{S}_{\mathrm{am}}
$$

where:

$$
\begin{aligned}
& \mathrm{S}_{\mathrm{am}}=1 / 6 \Sigma \mathrm{S}_{\mathrm{ai}} \\
& \mathrm{S}_{\mathrm{bm}}=1 / 6 \Sigma \mathrm{S}_{\mathrm{bi}} .
\end{aligned}
$$

Values which are entered to the formula (1) are obtained by measurement of samples according to the method presented on Figure 3.
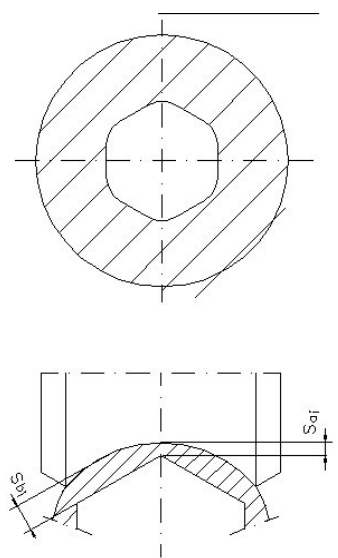

Fig. 3. The method of tube measurement for calculation of internal polygonization $P$ 


\section{EXPERIMENTS OF REDUCTION ROLLING OF TUBES WITH DIMINUTION OF INTER-STAND TENSION}

The aim of carrying out the experiments which are the subject of this study was proving the dependence between values of average coefficients of tension and values of polygonization P. Experiments of rolling were carried out on industrial stretch reduction rolling mill SRW300 consisting of 17 stands with individual drive made by Mannesmann Meer. For rolling there were used mother tubes of $\phi 91 \times 3,5 \mathrm{~mm}$, the same wall thickness, of the same batch, after induction welding in the same conditions. The result of experiments of reduction rolling were pipes of $\phi 33.7 \mathrm{~mm}$ with three other wall thickness sizes in each of series of experiments. Chemical analysis according to cast analysis of material used for experiments was the following: $0.10 \% \mathrm{C} ; 0.39 \% \mathrm{Mn} ; 0.01 \% \mathrm{Si} ; 0.021 \% \mathrm{~S}$ and $0.013 \% \mathrm{P}$. Three series of experiments were carried out, $\mathrm{nr} 1,2,3$, in the same conditions i.e. at the same temperature of tube entering to rolling mill. The temperature of mother tube entering the rolling mill amounted to $920-930{ }^{\circ} \mathrm{C}$ and temperature of pipe going out from rolling mill amounted to $860-870{ }^{\circ} \mathrm{C}$. Calculation for the reduction of rolling parameters in each series followed the method of equilibrium of axial forces developed by Mannesmann Meer, which is specified in the study [3]. This method consists of solving a system of equations of axial forces equilibrium for previously developed system of roll grove for rolling mill. The result of these calculations are coefficient values of tension between stands $z_{i}$ and then values of average coefficients in stands $z_{m i}$, values of wall thickness $s_{i}$ with the established values of coefficient of axial forces equilibrium $\mathrm{X}_{\mathrm{i}}$ of which possible values are shown on Figure 4 for each stand of the rolling mill. The last step for calculation of reduction rolling parameters is the specification of rotation speed of rolls given for defined velocity of the mother tube entering the rolling mill. The specification table of rolling parameters as a result of calculations after adjusting the parameters in the rolling mill ensures obtaining the wall thickness of finished tube from the mother tube which wall thickness is the result of the calculations. By lowering the coefficient of axial forces equilibrium $\mathrm{X}_{\mathrm{i}}$ in order to increase the wall thickness of rolled tube, in consequence of calculation new values of average tension are obtained as well as new values of wall of thicknesses for each of stands and new rotation speed of rolls for this values. According to this method the rolling parameters for each of the three series of experiments were calculated and more and more different wall thicknesses of tube were obtained as a result of systematic decrease of inter-stand tension. The expression (2) contains general form of the system of equations of axial forces equilibrium.

Figure 4 presents a schematic diagram of axial forces equilibrium in stretch reduction rolling mill and the ranges of coefficients values of axial forces equilibrium $\mathrm{X}_{\mathrm{i}}$ for stands which draws and brakes the tube during the rolling:

$$
\mathrm{Z}_{\mathrm{i}-1}+\mathrm{R}_{\mathrm{i}}= \pm \mathrm{X}_{\mathrm{i}} \mu \mathrm{N}_{\mathrm{i}}+\mathrm{Z}_{\mathrm{i}}
$$


where:

$$
\begin{aligned}
\mathrm{Z}_{\mathrm{i}-1} & \text { - axial component of tension before the stand; } \\
\mathrm{R}_{\mathrm{i}} & - \text { axial component of deformation resistance; } \\
\mathrm{X}_{\mathrm{i}} & - \text { coefficient of axial forces equilibrium; } \\
\mu & - \text { coefficient of friction; } \\
\mathrm{N}_{\mathrm{i}} & - \text { pressure of rolls to metal; } \\
\mathrm{Z}_{\mathrm{i}} & - \text { axial component of tension behind the stand. }
\end{aligned}
$$
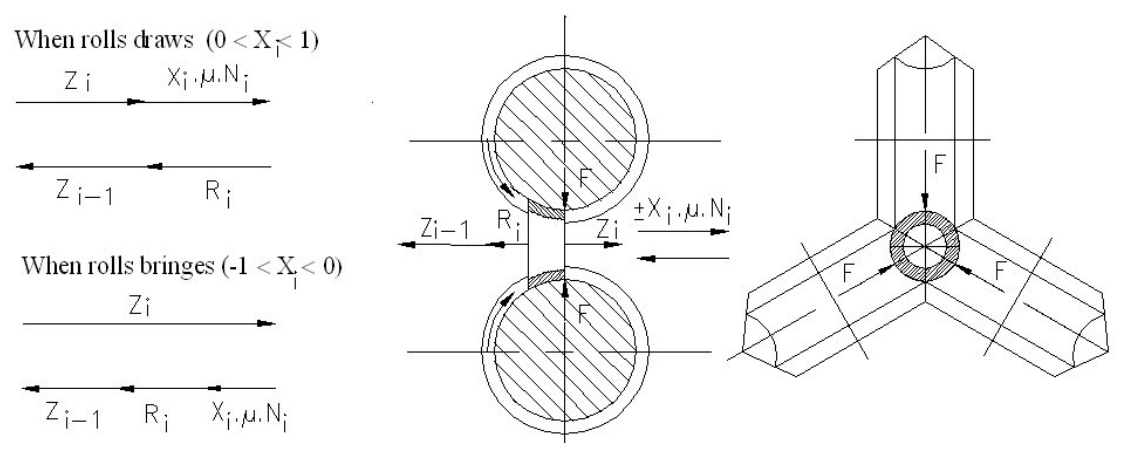

Fig. 4. The equilibrium of axial forces in a stand of stretch reducing mill

After calculating the rolling parameters three series of experimental rolling were carried out and in each of them rotation speeds of rolls were changed in order to decrease interstand tension in the next experiment. For each of series of experimental rolling the sample for measurement of internal polygonization was taken:

- sample no. 1, maximal values of inter-stand tension calculated by solving the system of equations of axial forces equilibrium with the coefficient of axial forces equilibrium $\mathrm{X}_{\mathrm{i}}=1$;

- sample no. 2, reduced values of inter-stand tension calculated by solving the system of equations of axial forces equilibrium with the coefficient of axial forces equilibrium $\mathrm{X}_{\mathrm{i}}=0.68$;

- sample no. 3, reduced values of inter-stand tension calculated by solving the system of equations of axial forces equilibrium with the coefficient of axial forces equilibrium $\mathrm{X}_{\mathrm{i}}=0.57$.

After the rolling the measurement of wall thickness of each tube sample was made according to the method shown in Figure 3 and then polygonization $\mathrm{P}$ was calculated. The results of measurements of wall thickness obtained for samples put together Figure 6 are shown in diagram (Fig. 5), the values of polygonizations are shown in diagram (Fig. 6). The results of solving the systems of equations of axial forces equilibrium for samples no. 1, 2, 3 are shown in diagram (Fig. 7). 


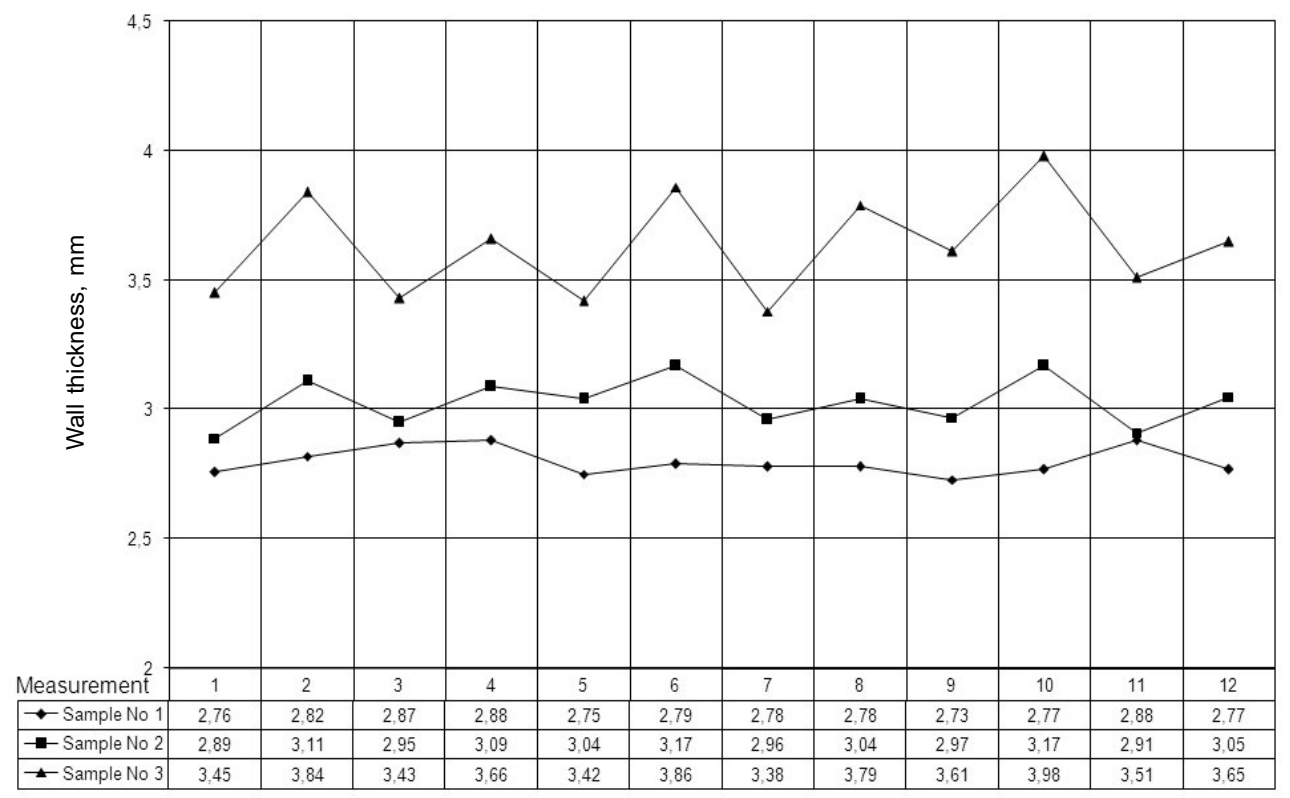

Fig. 5. The results of measurement of wall thickness performed each $\pi / 6$ on circumference of tubes samples no. 1, 2, 3

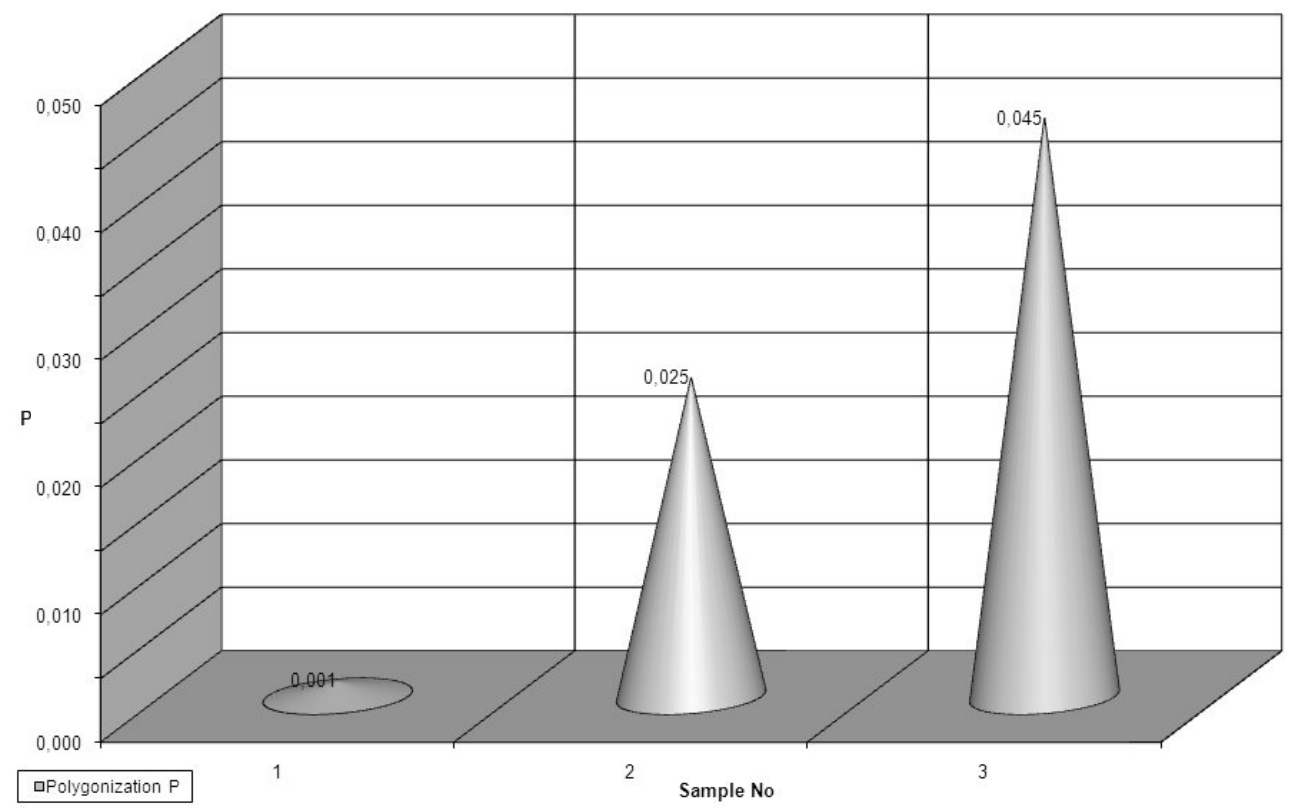

Fig. 6. Values of polygonization P for samples no. 1, 2, 3 
a)

Sample no. 1

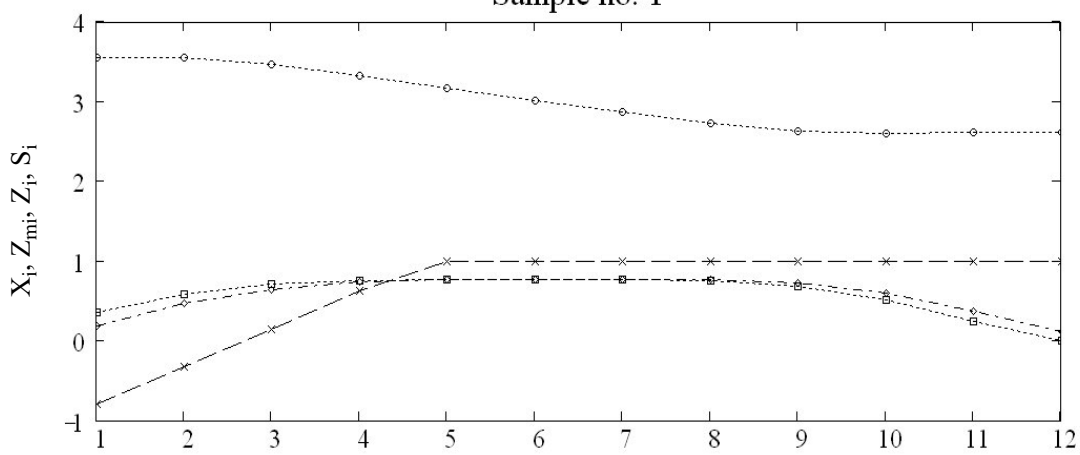

No. of stand (i)

b)

Sample no. 2

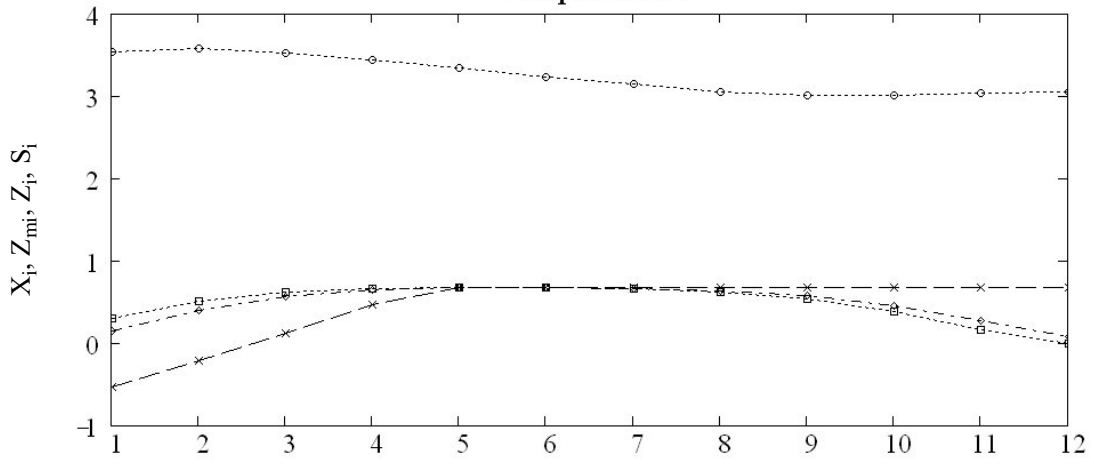

No. of stand (i)

c)

Sample no. 3

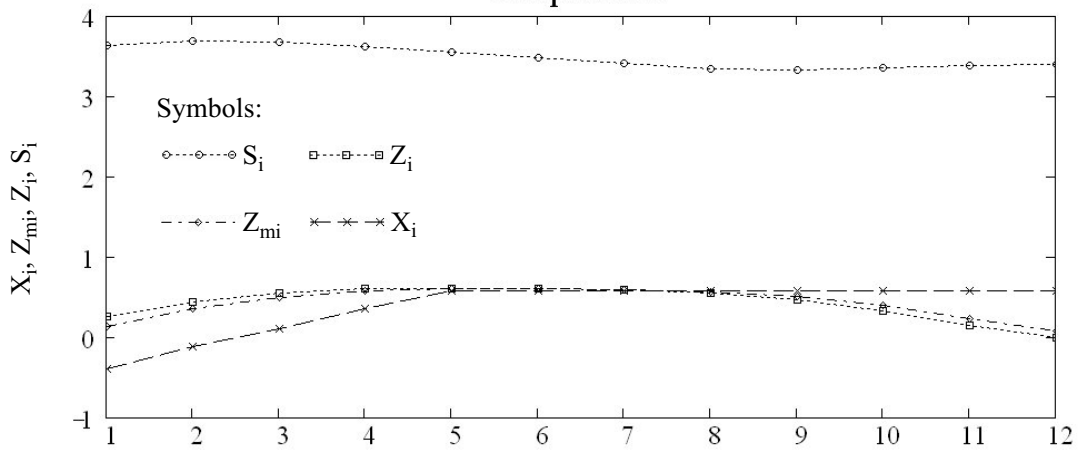

No. of stand (i)

Fig. 7. The results of solution for system of equations of axial forces equilibrium in stretch reduction mill for samples: no. 1 (a), no. 2 (b) and no. 3 (c) according to the method of Mannesmann Meer [3] 


\section{RESULTS OF TESTS}

Three series of experiments of hot stretch reducing rolling were carried out each time obtaining determined quantity of tubes from one of mother tubes. In each experiment of rolling the values of average tension in stands were decreased and the following results were obtained:

1. Very little internal plygonization of pipe in sample no. 1. Polygonization amounted to $\mathrm{P}=0.001$. The cross section of sample no. 1 as shown in Figure 8 does not display any visible polygonization. The wall thickness of pipe was reduced by about $20 \%$. The interval of the wall thickness of pipe amounted to $0.15 \mathrm{~mm}$.

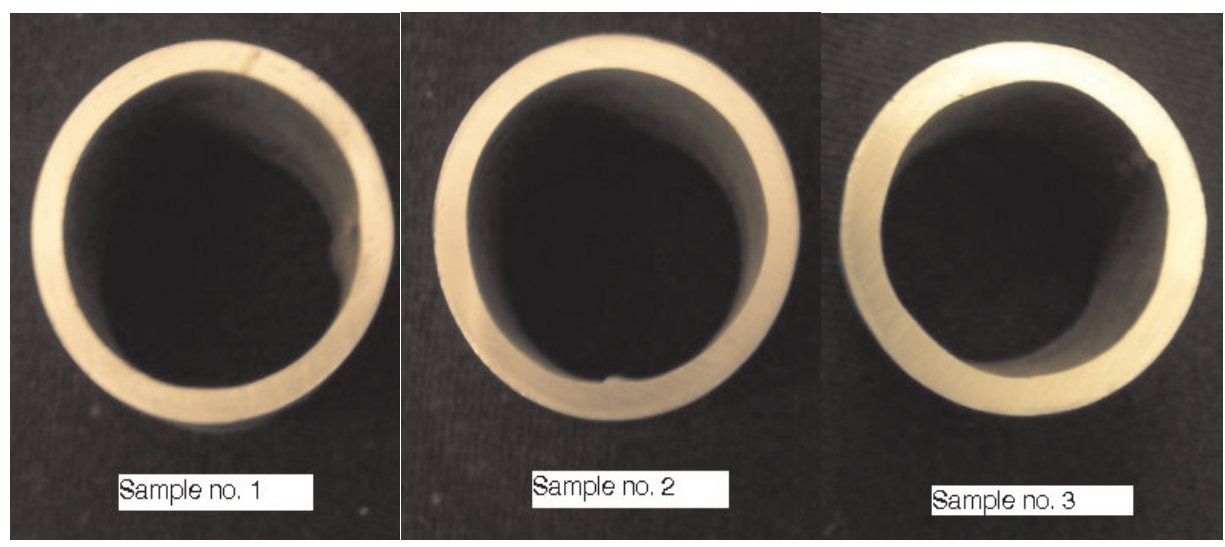

Fig. 8. Cross-sections of $\phi 33.7 \mathrm{~mm}$ pipe samples after hot stretch reduction rolling with maximal tension (sample no. 1) and with reduced tension (samples no. 2 and no. 3)

2. Small, visible internal polygonization of pipe in sample no. 2. Polygonization amounted to $\mathrm{P}=0.025$. The cross section of sample no. 2 as shown in Figure 8 displays visible, small polygonization. The wall thickness of pipe was reduced by about $15 \%$. The interval of the wall thickness of pipe amounted to $0.28 \mathrm{~mm}$.

3. Big internal polygonization of pipe in sample no. 3. Polygonization amounted to $\mathrm{P}=0.045$. The cross section of sample no. 3 as shown in Figure 8 displays visible, big polygonization. The average wall thickness of pipe is inconsiderably bigger than the wall thickness of mother tube (see Fig. 5). The interval of the wall thickness of pipe amounted to $0.56 \mathrm{~mm}$.

\section{CONCLUSIONS}

The analysis of test results allows drawing the following conclusions:

1. The smallest internal polygonization of tube takes place during hot stretch reduction rolling when it is carried out with the maximal average coefficients of tension $z_{\mathrm{mi}}$, suitable to equilibrium of axial forces. 
2. In order to receive the smallest internal polygonization during hot stretch reducing rolling of tubes and pipes it should be carried out with the optimal wall thickness of mother tube which lets to apply the maximal inter-stand tension ensured by equilibrium of axial forces.

\section{REFERENCES}

[1] Thieven P.: Untersuchungen zur Innenpollygobildung beim Streckreduzieren von Rohren, Stahl und Eisen, (1996) 8, 119-125

[2] Biller H.: Beitrag zum inneren Unrundwerden beim Reduzieren von Rohren, Diss. TH Aachen

[3] Kazanecki J.: Wytwarzanie rur bez szwu, UWN-D Wydawnictwa AGH, Kraków 2003

Received

May 2010 